\title{
@@- oPENACCESS ONE YEAR REVIEW OF PATIENTS ADMITTED WITH CARDIAC check for udatates DISEASES IN PREGNANCY IN A TERTIARY CARE HOSPITAL OF PESHAWAR
}

\author{
Shahzadi Saima Hussain, Tanveer Shafqat, Mehnaz Raees, Qudsia Qaziæ
}

Department of Obstetrics and Gynaecology, Medical Teaching Institute, Lady Reading Hospital, Peshawar - Pakistan

Address for correspondence: Qudsia Qazi

Department of Obstetrics and Gynaecology, Medical Teaching Institute, Lady Reading Hospital, Peshawar - Pakistan.

E-mail:

s_mmehdi@yahoo.com

Date Received:

September 16, 2020

Date Revised:

March 20, 2021

Date Accepted:

March 21, 2021
This article may be cited as

Hussain SS, Shafqat T, Raees M, Qazi Q. One year review of patients admitted with cardiac diseases in pregnancy in a tertiary care hospital of Peshawar. J Postgrad Med Inst 2021; 35(1):3-6. https://doi.org/10.54079/ jpmi.35.1.2776

\section{ABSTRACT}

Objective: To identify the frequency and type of cardiac diseases in pregnant women and their fetal and maternal outcome.

Methodology: This observational study was carried out in Unit A, Department of Gynecology and Obstetrics, Lady Reading Hospital, Peshawar from mid January 2019 to mid January 2020. After informed written consent, using non probability consecutive sampling all pregnant women presenting with cardiac diseases were included in this study. Age, parity, mode of delivery, and period of gestation were recorded. Cardiac disease was diagnosed on the basis of symptoms, ECG and echocardiography. Types of different cardiac lesions and maternal risk were noted according to Modified World Health Organization classification of maternal cardiovascular risk. Maternal and fetal outcomes were measured in terms of mortality. Data was analyzed using SPSS version 20.

Results: In one year, a total of 10263 pregnant ladies were admitted and among them $43(0.42 \%)$ patients had cardiac disease. It was observed that $79.1 \%(n=35)$ were diagnosed for 1 st time during pregnancy. Most frequent cardiac disorder was cardiomyopathy, found in $27.9 \%(n=12)$ of patients, followed by congenital heart disease in $18.6 \%(n=8)$, in the form of mitral and aortic stenosis. Maternal and fetal mortality was $4.7 \%(n=2)$ and $9.3 \%$ $(\mathrm{n}=4)$, respectively.

Conclusion: There is a small proportion of pregnant patients with cardiac disease among all pregnancies. Most of the patients were multiparous and cardiomyopathy was found to be the most prevalent cardiac disease.

Key Words: Heart disease; Maternal mortality; Pregnancy; Cardiovascular diseases; Fetal mortality

\section{INTRODUCTION}

Cardiac disease in pregnancy is among one of the leading indirect causes of maternal mortality throughout the world. In pregnancy $1-4 \%$ of women are affected by heart disease. In developed countries acquired heart diseases is major concern while in developing countries it is both congenital and acquired heart disease that adds significantly to maternal mortality and morbidity. ${ }^{1-3}$

In pregnancy there are many physiological changes in cardiovascular system, like increase in plasma volume, red cell mass, cardiac output, heart rate, stroke volume, relaxation of smooth muscles leading to increased capacitances of venous bed and decrease in peripheral vascular resistance. Labour adds to work load on heart as there is further increase in heart rate and cardiac output. In $3^{\text {rd }}$ stage of labour because of return of up to one liter of blood back to systemic circulation blood volume and cardiac output increase further. Women with compromised heart are at most risk of complications and $2^{\text {nd }}$ stage of labour and immediately after delivery. ${ }^{4}$
The risk of woman developing a cardiovascular problem during pregnancy is on rise because of increase in obesity, diabetes, hypertension and delaying pregnancy to later age. It is important to evaluate every pregnant patient for cardiac disease because it can lead to tremendous increases in risk of dying in pregnancy as compared to healthy pregnant women. ${ }^{5,6}$

Despite of its significant impact on maternal health, it remains undiagnosed in most cases until complications arise. Even in countries with better health care system like United Kingdom, majority of women who died of heart disease had no prior diagnosis of heart disease. One of the reasons is either lack of awareness or inappropriate knowledge of health care providers related to risks and management of cardiac diseases in pregnancy. ${ }^{5,7}$

World Health Organization (WHO) has classified heart diseases in four classes according to type of cardiac disease. These classes from I-IV represent low to high risks of cardiac disease in pregnancy. It is useful system in assessing risk and also to guide obstetrician about management and any need of referral. ${ }^{8}$ 
In third world countries like Pakistan, direct causes of maternal morbidity and mortality like obstetric haemorrhage, pre eclampsia, sepsis and miscarriage are highlighted more and less research and importance is given to indirect causes like cardiac disease in pregnancy, evident by lack of national statistics available on incidence and prevalence of this diseases. This study was conducted to find out the frequency of cardiac diseases in pregnancy and also to find out which type of cardiac disease is most common in this part of the world. Literature review suggest that no such study is conducted locally, though few relatable studies are conducted in other provinces of Pakistan. This study will enlighten us with disease burden and type, as well as it will create awareness among healthcare providers and pregnant women on importance of the subject leading to improve prevention, diagnosis and management of cardiac diseases during pregnancy.

\section{METHODOLOGY}

This prospective cross sectional study was carried out in Department of Gynecology and Obstetrics, Lady Reading Hospital, Peshawar from January 2019 to January 2020, after approval from hospital ethical committee. Written informed consent was obtained. Using non probability consecutive sampling, all pregnant women who were presented with suspected cardiac diseases were included in this study (patients with symptoms of shortness of breath, easy fatigability, chest pain and frequent palpitations). The diagnosis was confirmed with electrocardiogram and echocardiography in liaison with cardiologist. Patients with known prior diagnosis were also included in this study, those who had symptoms of cardiac disease but were not able to get echocardiography and ECG (due to multiple reasons) were excluded. Quantitative variables like age, parity, mode of delivery and period of gestation was noted. Gestation age was calculated from dating ultrasound, date of Last menstrual period. Parity was divided into three groups, primiparous, multi parous (parity was between 2-5), and grand multiparous with parity more than 5 . History of previously diagnosed cardiac disease. Any cardiac surgery or intervention was also re- corded. Mode of delivery was noted in terms of Normal Vaginal Delivery (NVD), Assisted Vaginal Delivery (AVD) where either vacuum cup or forceps were used to deliver baby, and Caesarean Section (CS). Maternal and fetal outcome were noted in terms of mortality. According to "Modified WHO classification of maternal cardiovascular risk" ${ }^{\prime}$, types of cardiac lesions and maternal risk were noted. Primary outcome was to know frequency and most frequent type of cardiac disease. Maternal and fetal outcome were measured in terms of mortality as secondary outcome of study. Data was analyzed using SPSS version 20. Numerical data was measured as mean $\pm \mathrm{SD}$, while categorical data was expressed in frequency and percentages.

\section{口ESULTS}

In one year, a total of 10263 pregnant ladies were admitted. Among them, 43 $(0.42 \%)$ were found to have cardiac disease while 31 (79.06\%) were diagnosed for the first time during pregnancy. Most of the patients ( $n=31,72.1 \%$ ) were multiparous. It was noted that $26(60.5 \%)$ presented at term. Majority of patients $(n=34,79.1 \%)$ had normal vaginal delivery. The details are given in table 1. Maternal mortality was reported in 2 (4.65\%) patients (Table 2). Cardiomyopathy was found in a total of 12 (27.9\%) patients. Further details are given in table 3.

\section{- DISCUSSION}

Cardiac disease in pregnancy has adverse impact on maternal mortality and morbidity. Both in developed and developing countries underlying cardiac disease is not diagnosed until complications appear. So this is strong reason to believe that actual patients having heart disease may be more than reported. In our study, $0.42 \%$ of the obstetric patients were found to have heart diseases. In similar studies in Pakistan, the prevalence of cardiac disease was $0.21 \%$ and $0.98 \%{ }^{3,9}$ Poor health facilities may attributed to be a probable reason and woman with heart disease remain undiagnosed.

In two different studies, about $42.3 \%$ and $65 \%$ had their first diagnosis of cardiac disease in pregnancy. ${ }^{3,10}$ The relative high num- ber of patients who were diagnosed in pregnancy in our study may be due to fact that majority of women live in rural areas, with poor healthcare facilities and less awareness about symptoms. All this leads to delay in seeking care.

In our study, most frequent cardiac disorder was cardiomyopathy, found in $27.9 \%$ of patients. Out of these $23.3 \%(n=10)$ had severe ventricular dysfunction with ejection fraction $<40 \%$. Similar figures were reported in United Kingdom where cardiomyopathy was leading cardiac disorder (27\%) among pregnant women with cardiac disease, who died. ${ }^{5}$ However, our result was high in comparison to studies conducted in other parts of Pakistan where it has been reported as 5.7\% and $14.2 \%{ }^{3,11}$ This may be an incidental finding or there may be a paradigm shift in the type of disease. We need more studies and research to find out the causes of higher rate of cardiomyopathy in this part of the world.

It was observed in this study that $18.6 \%$ had congenital heart disease in form of atrial septal defect / ventricular septal defect and mitral valve prolapse. In half of the cases, it was previously repaired. Frequency of similar lesions was 28\% and 23\% in other cities of Pakistan. ${ }^{3,9}$ Internationally the number of patients with $\mathrm{CHD}$ in pregnancy is far high $(57 \%)^{12}$

Mitral stenosis is another common but series condition especially in pregnancy. The most common cause is rheumatic heart disease. In our study $18.6 \%$ patients had severe mitral/ aortic stenosis. Our results are almost similar to another study in Pakistan that reported severe mitral and aortic stenosis in $20 \%$ of pregnant women, the figures shared by European Registry of Pregnancy and Cardiac diseases (ROPAC), which reported that $19.8 \%$ of pregnant patients had severe mitral stenosis. ${ }^{9,12}$

In our study, the mortality rate of pregnant women was $4.6 \%$. A similar local study reported maternal mortality of $5.7 \%{ }^{3}$ This higher mortality figure reflects poor health care system and delay in seeking treatment. Neonatal mortality in our study was $9.3 \%$. A similar study in Pakistan reported to have 7\% mortality, while a study in Iran showed 10\% neonatal mortality. ${ }^{10,13}$ 
One year review of patients admitted with cardiac disease in pregnancy in a tertiary care hospital of Peshawar

Table 1: Demographic features

\begin{tabular}{|c|c|c|c|}
\hline \multicolumn{2}{|c|}{ Demographic features } & Number of patients & Percentage \\
\hline \multirow{3}{*}{ Parity } & Primigravida & 8 & 18.6 \\
\cline { 2 - 4 } & Para 2 - Para 5 & 31 & 72.1 \\
\cline { 2 - 4 } & $>$ Para 5 & 4 & 9.3 \\
\hline \multirow{3}{*}{ Mode of delivery } & Normal vaginal delivery & 34 & 79.1 \\
\cline { 2 - 4 } & Assisted vaginal delivery & 7 & 16.2 \\
\cline { 2 - 4 } & Cesarean section & 2 & 4.7 \\
\hline \multirow{3}{*}{ Gestational age (Weeks+days) } & $<24$ & 3 & 7 \\
\cline { 2 - 4 } & $24+1-36+5$ & 14 & 32.5 \\
\cline { 2 - 4 } & $37-42$ & 26 & 60.5 \\
\hline
\end{tabular}

Table 2: Maternal and fetal outcomes

\begin{tabular}{|c|c|c|c|c|}
\hline \multicolumn{3}{|c|}{ Outcome } & Number of patients & Percentage \\
\hline \multirow{3}{*}{ Maternal } & & Alive & 41 & 95.34 \\
\hline & \multirow{2}{*}{ Dead } & Severe pulmonary arterial hypertension & 1 & 2.33 \\
\hline & & Cardiomyopathy & 1 & 2.33 \\
\hline \multirow{2}{*}{ Fetal } & \multicolumn{2}{|r|}{ Alive } & 39 & 90.69 \\
\hline & \multicolumn{2}{|r|}{ Dead } & 4 & 9.31 \\
\hline
\end{tabular}

Table 3: Frequency of types of cardiac lesions according to World Health Organization (WHO) Risk Scoring

\begin{tabular}{|c|c|c|}
\hline \multicolumn{2}{|r|}{ Types of lesions } & $\mathrm{n}=43$ \\
\hline \multirow{5}{*}{ WHOI } & Uncomplicated small or mild pulmonary stenosis & 2 \\
\hline & Uncomplicated small or mild patent ductus arteriosus & 0 \\
\hline & Uncomplicated small or mild mitral valve prolapse & 3 \\
\hline & Successfully Repaired atrial septal defect / ventricular septal defect and patent ductus arteriosus etc. & 2 \\
\hline & Atrial or ventricular ectopic beats & 1 \\
\hline \multirow{3}{*}{$\begin{array}{l}\text { WHO II (if otherwise } \\
\text { well and uncompli- } \\
\text { cated) }\end{array}$} & Unoperated atrial or ventricular septal defect & 3 \\
\hline & Repaired tetrology of Fallot & 0 \\
\hline & Most arrhythmias & 1 \\
\hline \multirow{4}{*}{$\begin{array}{l}\text { WHO II-III (depend- } \\
\text { ing on individual) }\end{array}$} & Mild left ventricular impairment & 0 \\
\hline & Hypertrophic cardiomyopathy & 2 \\
\hline & Native or tissue valvular heart disease not considered WHO I or IV & 1 \\
\hline & Marfans syndrome without aortic dilation, aorta $<45 \mathrm{~mm}$ in aortic disease with bicuspid aortic valve & 1 \\
\hline \multirow{6}{*}{ WHO III } & Mechanical valves & 0 \\
\hline & Systemic right ventricle & 0 \\
\hline & Fontan's circulation & 0 \\
\hline & Cyanotic heart disease (Unrepaired) & 0 \\
\hline & Other complex congenital heart disease & 0 \\
\hline & $\begin{array}{l}\text { Marfans syndrome with aortic dilatation }>45 \mathrm{~mm} \text {, Aortic dilatation }>50 \mathrm{~mm} \text { in aortic disease with bicuspid } \\
\text { aortic valve }\end{array}$ & 0 \\
\hline \multirow{6}{*}{$\begin{array}{l}\text { WHO IV (pregnancy } \\
\text { contraindicated) }\end{array}$} & Pulmonary arterial hypertension of any cause & 6 \\
\hline & Severe systemic ventricular dysfunction ((LVEF <30\%) & 10 \\
\hline & Previous peripartum cardiomyopathy with any residual impairment of left ventricular dysfunction & 2 \\
\hline & Severe mitral stenosis, severe symptomatic aortic stenosis & 8 \\
\hline & $\begin{array}{l}\text { Marfans syndrome with aortic dilatation } 40-45 \mathrm{~mm} \text {, Aortic dilatation } 45-50 \mathrm{~mm} \text { in aortic disease with bicuspid } \\
\text { aortic valve }\end{array}$ & 0 \\
\hline & Native severe coarctation & 0 \\
\hline \multicolumn{2}{|c|}{ Myocardial infarction (not included in WHO Classification ) } & 1 \\
\hline
\end{tabular}




\section{CONCLUSION}

The study concluded that there is a small proportion of pregnant patients with cardiac disease among all pregnancies. Most of the patients were multiparous and cardiomyopathy was found to be the most prevalent cardiac disease in the settings under study. More such studies are required to elaborate the type and burden of heart diseases in this part of world.

\section{REFERENCES}

1. Nickens $\mathrm{M}$, Long $\mathrm{R}$, Geraci S. Cardiovascular disease in pregnancy:-( women's health series). South Med J. 2013;106(11):624-30. https://doi. org/10.1097/SMJ.0000000000000015.

2. Trinidad D, Cox RA. Heart diseases during pregnancy. P R Health Sci J. 2006;25(3):259-65.

3. Ansari A, Akram U, Khattak S, Rabbani $F$, Khalil H. Risk scoring and outcome in pregnant cardiac patients in a peripheral tertiary care centre. Pak Armed Forces Med J. 2019;69(1):15-20.

4. Piercy $\mathrm{CN}$. Heart disease in pregnancy. In: Edmonds K, editor. Dewhurst's textbook of
Obstetrics and Gynaecology (Eighth edition): John Wiley \& Sons; 2011. p.11120.

5. Murphy JF. Mothers and babies-reducing risk through audits and confidential enquiries. Ir Med J. 2012;105(7):228.

6. Jastrow N, Meyer P, Khairy P, Mercier LADore A, Marcotte F, Leduc L. Prediction of complications in pregnant women with cardiac diseases referred to a tertiary center. Int J Cardiol. 2011;151(2):20913. https://doi.org/10.1016/j.ijcard.2010.05.045.

7. Vause S, Thorne S, Clarke B. Preconceptional counselling in woman with cardiac disease.in: Steer PJ, Gatzoulis MA, editors. Heart disease and pregnancy. Cambridge University Press; 2016.p.1 https:// doi.org/10.1017/CB09781316156063.

8. European society of gynecology (ESG); Association for European Paediatric Cardiology (AEPC); German society for gender medicine (DGesGM), Regitz-Zagrosek V, Blomstrom Lundqvist C, Borghi C, et al; ESC Committee for practice guidelines. ESC Guidelines on the management of cardiovascular diseases during pregnancy: the task force on the management of cardiovascular diseases during pregnan- cy of the European society of cardiology (ESC). Eur Heart J. 2011;32(24):314797. https://doi.org/10.1093/eurheartj/ ehr218.

9. Asghar F, Kokab H. Evaluation and outcome of pregnancy complicated by heart disease. J Pak Med Assoc. 2005;55(10):416-9.

10. Wasim T, Amer W, Majrroh A, Siddiq S. Foetomaternal outcome of pregnancy with cardiac disease. J Pak Med Assoc. 2008;58(4):175-8.

11. Latif L, Iqbal UJ. Prevalence of cardiac diseases. Professional Med J. 2015;22(11):1443-8. https://doi. org/10.17957/TPMJ/15.2990

12. Roos-Hesselink J, Baris L, Johnson M, De Backer J, Otto C, Marelli A, et al. Pregnancy outcomes in women with cardiovascular disease: evolving trends over 10 years in the ESC Registry Of Pregnancy And Cardiac disease (ROPAC). Eur Heart J. 2019;40(47):3848-55. https://doi. org/10.1093/eurheartj/ehz136.

13. Yaghoubi A, Mirinazhad M. Maternal and neonatal outcomes in pregnant patients with cardiac diseases referred for labour in northwest Iran. J Pak Med Assoc. 2013;63(12):1496-9.

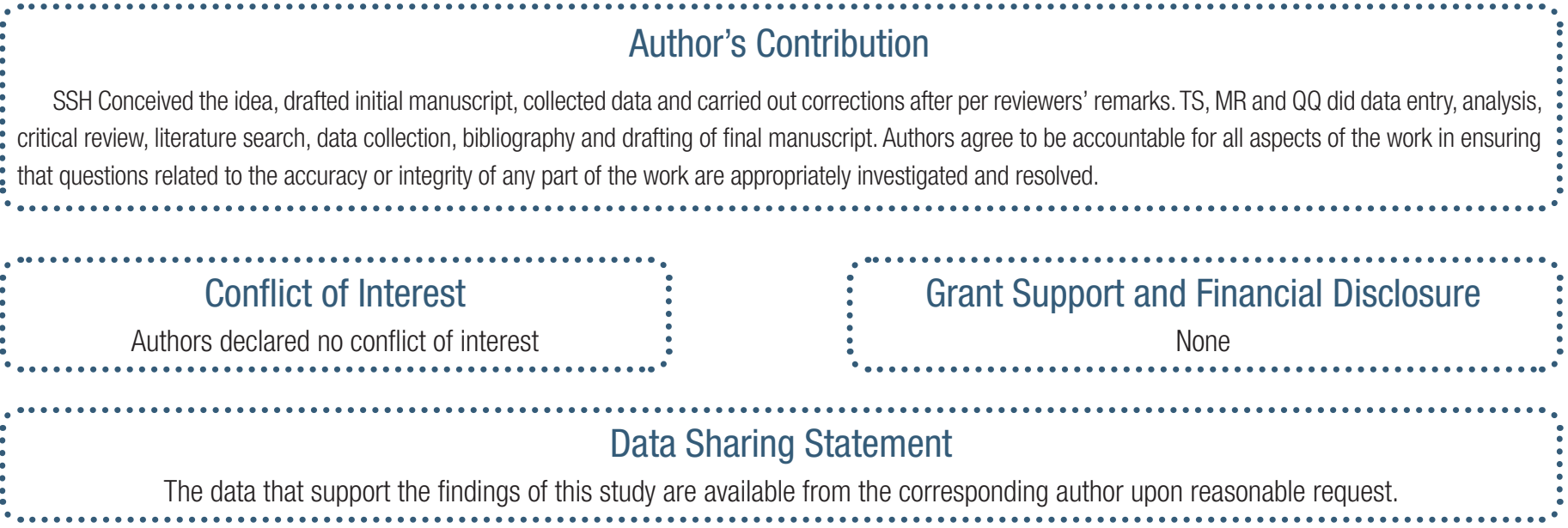

